\title{
A framework for access to the conservation-restoration profession via the mapping of its specialist competencies
}

\author{
Jeremy Hutchings • Susan Corr
}

Published online: 4 June 2011

(C) The Author(s) 2011. This article is published with open access at Springerlink.com

\begin{abstract}
The paper describes how specific descriptors for the Conservation-Restoration profession have been developed by the European Confederation of Conservator-Restorers' Organizations. The result of which is in accordance with the threefold rubric of Knowledge, Skills and Competence as defined by the European Qualifications Framework. Instead of giving a broad general description of level, which is insufficiently expressive, concept mapping has been used to explicitly uncover the topography of Knowledge, Skills and Competence required for access to the profession. The application of this method, originally developed by Novak in 1972 to enhance learning in the sciences, demonstrates that it is possible to elucidate the complex nature of such professions using such a declarative system. Its hierarchical nature and the ease with which links between different elements can be identified aid the construction of an intellectually robust framework, thereby demonstrating its appropriateness. The results suggest that access to the profession can be presented as a framework of interconnected cognitive competencies, which can be expressed as a structural process where each element possesses an individual level of skill and knowledge.
\end{abstract}

Keywords European qualification framework - Conservation-restoration · Concept map · Skill $\cdot$ Knowledge $\cdot$ Competence $\cdot$ Taxonomy $\cdot$ Entry qualifications · E.C.C.O

\section{Introduction}

This paper presents the work undertaken by the European Confederation of ConservatorRestorers' Organizations (E.C.C.O.) to explicitly define the level and scope of competence required by those wishing to enter the Conservation-Restoration profession. Competence

J. Hutchings $(\bowtie)$

Institute of Archaeology, Conservation and History, University of Oslo, Postbox 1008, Blindern, Oslo, Norway

e-mail: j.d.hutchings@iakk.uio.no

S. Corr

MICHAWI, Corrandulla, Co, Annaghdown, Galway, Ireland 
in this context is the end result of an education process that provides an aspiring professional with the ability to achieve and deliver work to a level consistent with professional requirements within their specialist field. While this approach encompasses the professional "requisites", in terms of the threefold rubric of skills, knowledge and competence, inherited from the European Qualification Framework (EQF) system, it attempts to avoid the prescriptive nature of this system. This is achieved by focusing on the level of "knowingness" needed by someone entering the profession rather than attempting to specify the actual knowledge and skills considered necessary to carry out a particular task within a given set of circumstances.

The research makes innovative use of concept mapping, developed by Novak in 1972 (Novak and Musonda 1991). Although this technique was originally developed as a way of enhancing meaningful learning in the sciences, it can be applied in this case because of its capacity to present visually the organisation of a declarative system, thereby facilitating sense-making within a complex environment. Unlike other visualization techniques, such as mind mapping, its hierarchical nature and the ease with which links between different concepts can be identified and described aid the construction of an intellectually robust framework. While this application is outside the original scope of concept mapping, it is demonstrated through this work to be an appropriate means of achieving a negotiated and well defined representation of the levels of knowledge and skill required to enter the profession.

\section{Background}

The impetus for this initiative came from a formal request to develop descriptors for the profession, issued in November 2006 by the EU Commissioner responsible for Education, Training, Culture and Youth. The request was the consequence of the adoption of a system of easily understandable and comparable degrees within the European Higher Education Area (EHEA) formed under the Bologna Declaration (EU 1999). The aim of this declaration is to reform the structures of the higher education system in member countries in a convergent way by calibrating and making explicit the educational qualifications awarded by all third level education providers throughout Europe.

The European Qualification Framework (EQF) was formally adopted by the European Parliament and Council on 23 April 20089 years after the signing of the Bologna Declaration. Its purpose is a reference tool to aid concordance between qualification levels of the different educational systems throughout Europe with the aim of improving the transparency, comparability and portability of qualifications issued within the different Member States. Its widespread adoption should "enable international sectoral organisations to relate their qualifications systems to a common European reference point and thus show the relationship between international sectoral qualifications and national qualifications systems". Pan-European professional bodies, such as E.C.C.O. are encouraged to become involved in this process through the specification of entry requirements for the professions that they represent. The education providers that service the professions will then be expected to offer courses that meet these requirements. Metaphorically these entry requirements can be expressed as the door through which students of Conservation-Restoration pass through when graduating. The combined learning outcomes of ConservationRestoration education must therefore correspond to a particular entry point for a particular specialisation within the profession, represented by an appropriate balance of knowledge, skill and competences. As will be discussed, the work undertaken by E.C.C.O. on 
professional competence adopts this rubric in order to maintain direct comparability with education and makes explicit its use as an evaluative tool for entry into the ConservationRestoration profession and for a potentially useful tool for continuing professional development. The start of the project undertaken by E.C.C.O. followed a mandate in 2007 given at its General Assembly. The work however was delayed until after the 2008 General Assembly when a working group, comprising of representatives from six of the member European country's Conservation-Restoration professional bodies, was formed.

\section{The conservation-restoration profession}

Conservation-Restoration is an empirical science devoted to the preventive and remedial treatment of cultural heritage objects (ENCoRE 2001). On a professional level, it can be characterised as a combination of a high level of theoretical knowledge and practical skills, including the ability to make ethical and aesthetic judgements in a systematic way (Larsen 2008). While the profession originates from highly skilled craftsmanship and the arts, it has developed academically during the latter half of the twentieth century to include humanistic and natural sciences, applied chemistry and physics, as well as analytical, organisational and philosophical elements. The demands made on a person entering the profession is therefore characterised by its diversity, which includes:

- An understanding of the role of cultural heritage in society

- a detailed understanding of the risks to cultural heritage

- well developed practical skills within a specialisation

- systematic problem solving skills

- broad knowledge of historic and modern materials and their properties

- broad knowledge of the behaviour of historic and modern materials under the influence of external factors

- a detailed knowledge of the methods of preventing damage

- a detailed knowledge of the treatment of damage and decay

- an ability to make aesthetic judgements

- an ability to make ethical judgements

From an educational point of view, few if any higher education programmes in other fields require such a diverse curriculum, which spans the sciences and humanities. This combined with the relative newness of many of the university Conservation-Restoration education programmes, and the different traditions across Europe, means that educational approaches are diverse and many are still actively evolving. The European Network for Conservation-Restoration Education, ENCoRE, founded in 1997 with the main objective of promoting research and education in the field of cultural heritage, is a unifying force within this evolution. Its formation resulted from the directions and recommendations given in E.C.C.O.s first Professional Guidelines (E.C.C.O. 1997) and the Document of Pavia (ENCoRE 1997). The second set of professional guidelines, Clarification of Conservation-Restoration Education atUniversity level or recognised equivalent, published by ENCoRE in 2001, describes Conservation-Restoration as an empirical science based on the highest level of research (ENCoRE 2001). While the multi-disciplinary nature and objectives of Conservation-Restoration are represented in this document it falls short of explicitly defining the levels of skills, knowledge and competence required to enter the profession. Neither does it explain how the application of the relevant knowledge and skill characterise the conservation-restoration process itself. 
The third set of Guidelines, reissued by E.C.C.O. in 2004, partially filled this lacuna describing the minimum level of education for entry into the profession as "Master's level (or recognized equivalent)", which "should be achieved by a period of full-time study in Conservation-Restoration of no less than 5 years" (CON.BE.FOR 2000; E.C.C.O. 2004). This equates to a combined Bachelor (BA) and Master (MA) education or 300 European Credit Transfer (ECT) points. The BA is regarded by E.C.C.O. and ENCoRE as an entry requirement for the MA, not a qualification for independent professional practice in conservation (Larsen 2008). The 2004 Guidelines emphasise the need for a good balance of theoretical education and practical training to ensure that graduates are able to "work responsibly in the field of Conservation-Restoration of cultural heritage" (E.C.C.O. 2004). While these offer the most detailed advice for Conservation-Restoration education to date, they remain too general to be used for the systematic characterization of the education standards. The work presented here is a natural development of these guidelines in line with demands currently made by Europe.

\section{The mandate and approach}

Following a meeting with the EU Commissioner in December 2006, E.C.C.O. undertook to write specific descriptors defining the level in the European Qualification Framework for entry into the Conservation-Restoration profession. This interprets the generic EQF descriptors in accordance with the threefold rubric of Knowledge, Skills and Competence as they define learning outcomes. The specific descriptors, in order to represent the qualifications for access to the profession, need to encompass the full range of professional demands likely to be placed on a recent graduate. Logically these will reflect learning outcomes irrespective of the institutional context, work or study situation, or whether they have been gained through workplace or vocational education. It was unanimously agreed at the E.C.C.O. General Assembly 2007 that the entry point into the profession, as defined by this organisation's Professional Guidelines, corresponded to EQF Level 7. The first challenge for the working group was to examine each of the three generic EQF descriptors at this level, and then to interpret them in terms of access to the Conservation-Restoration profession. The immediate result would ideally define the knowledge, skills and competences qualified by the generic language of the EQF at that level. This however proved to be difficult.

The problem with a direct approach to defining the descriptors for both education and access to a profession became immediately apparent: a single statement was too general to be meaningful. It ran the risk of becoming both prescriptive and outmoded from the outset, giving rise to the distinct danger that a simple statement of knowledge, skills and competence would cause access requirements to become fixed. Such a static approach would inevitably act as an impediment to the creation of new knowledge and consequently hinder the development of the profession. While not directly related to the construction of a descriptor, other issues were identified and needed to be addressed before access to the profession could be defined, these included:

1. No frame of reference can be considered as neutral; the theoretical approaches and analytical tools that are adopted will undoubtedly influence the way in which the subject is understood;

2. Over-riding cultural factors may exist that shape how the key competences are interpreted, such as the development of Conservation-Restoration in a given country and to a lesser extent social and gender issues; and 
3. The relationship between a conceptual model, its interpretation and its implementation within a particular set of circumstances within a particular country is not likely to be linear.

A practical obstacle that needed to be overcome was the obvious demand to restrict key competences to a manageable number. In reality, there is a multitude of possible approaches to Conservation-Restoration as well as a diversity of duties and tasks carried out by the professional conservator. It is, of course, impossible to adequately describe all of these duties and tasks while a single general description becomes increasingly irrelevant as the diversity of the profession expands. This is especially true considering the multiplicity of national and regional perspectives that already exist throughout Europe. Indeed, from this perspective defining and selecting a universally representative set of competences for all wishing to enter the profession of Conservation-Restoration throughout Europe raised a number of issues from the onset, including:

- Different levels of education are accepted in order to practice as a conservator-restorer in different countries across Europe (E.C.C.O. 2009).

- The various Conservation-Restoration traditions within different countries, which result in different approaches to, and delivery of, their respective educational programmes.

- The diverse number of disciplines that fall under the umbrella term of ConservationRestoration, for example: paintings restoration, furniture conservation and archaeological conservation. Each has different traditions, ethical and practical approaches. The material itself impacts on how key competences are defined, developed, transmitted and assessed.

Acknowledgement of these issues steered the approach adopted by E.C.C.O. towards a more fundamental examination of both the EQF and the conceptual role of a ConservatorRestorer. It brought to the forefront the hierarchical principle of the EQF in terms of increased knowledge, skills and competence as learning proceeded, confirming the validity of research that examined progress through the levels as a process of learning. If this process, exemplified by increasing complexity of the generic descriptors in the EQF, is further untangled, it is a specific point within the paradigm of expanding knowledge, skills and competences that must correlate to the appropriate access points for the ConservationRestoration profession, not a defined area knowledge skill and competence expressed in absolute terms. In this sense someone entering the profession has reached a level of "knowingness" where they have collected sufficient knowledge, skill and competence to accept responsibility and operate within the ethical norms of Conservation-Restoration within a certain specialism. In these circumstances competence is considered synonymous with attributes such as: qualifications, ability to perform complex tasks effectively, aesthetic judgement and decision-making. It is closely associated with a level of responsibility that allows autonomy, although the relationship between the two is less clear. This is partially due to responsibility being a social construct which is assigned to actions of an individual that is perceived as trustworthy. As such it relies on a qualitative judgement of actions based on concepts such as reliability, confidence and expectations, which are influenced by an individual's standpoint and social precepts. In reality this represents a dichotomy between the position, perception and knowledge of the individual making the judgement and the actual expertise of the person being judged.

The construction of a framework that reflected the role of Conservation-Restoration in easily legible terms allowed the exploration of competence through the application of the 
learning process hierarchy. This in turn characterises the topography of skills and knowledge that represented the basic attributes of a professional conservator-restorer. The technique of concept mapping provided the freedom to explore this paradigm without being prescriptive and without having to rely on a set of scenarios. Recognising that the acquisition of knowledge, skills and competence is both cumulative and heuristic, the working group sought to apply the learning-process hierarchy proposed by Anderson and Krathwohl (2001) as a narrative to the conceptual framework.

Even here it must be acknowledged that the level of knowledge, skills and competence required to enter a profession is not the same as the level expected from someone who has practiced for a number of years within the same profession and who is judged by fellow professionals as an expert in their field. For instance, it was universally agreed that within the knowledge category, 'highly specialised knowledge', which is the EQF Level 7 descriptor, better describes a practitioner after several years experience then someone who has just entered a profession and is at the beginning of their career. Within the context of this work, the paradox between the EQF language and profession language was considered in an attempt to allow space for continuous professional development to occur within Level 7, the latter having already been recognised as a requirement within Conservation-Restoration (Lester 1999). This paradox highlights a short-coming associated with The European Qualification Framework - the eight point scale is limited to formal education up to $\mathrm{PhD}$ level. It does not take into consideration continuous professional development past this point nor post-doctoral research, both of which are common within this profession.

The final stage of framework development was to apply this same hierarchy of learning processes to the levels above and below EQF Level 7. This expanded the conceptual map into a third dimension allowing the increasing in knowledge, skills and competence to be defined between the levels. The sections that follow present the stepwise process that has been described followed.

\section{Interpreting the EQF generic descriptors}

The working group recognised that the definitions offered by EQF could not be directly transcribed for the Conservation-Restoration profession as they contained a high level of ambiguity. Without possessing a clear concept of competence, which has already been argued as being synonymous with professional status, any attempt to define the entry requirements of a profession is at risk. E.C.C.O. therefore started by interpreting the language used by the generic EQF descriptors for Level 7 and benchmarking it against the Conservation-Restoration professional norms:

The generic level of knowledge at EQF Level 7 is:

Highly specialised knowledge, some of which is at the forefront of knowledge in a field of work or study, as the basis for original thinking and/or research. Critical awareness of knowledge issues in a field and at the interface between different fields. (The European Qualification Framework for Lifelong Learning, European Communities, 2008:12)

In order to interpret this definition it was necessary to understand the perspective from which it had been constructed. Rather than taking highly specialised knowledge as meaning "an expert with the highest competence or achievement within a professional field", which equates to a grand master and therefore could not be expected from someone entering a profession, it was interpreted as the knowledge in a field of Conservation-Restoration that 
is only attained following an education combining "an appropriate balance of integrated theoretical and practical teaching...." (ENCoRE 1997, clause 6). Critical awareness of knowledge issues in a field was interpreted as an understanding of the knowledge required, including the ability to acquire new knowledge, evaluate its validity and reliability, and apply it, in order to justify all decisions within the conservator-restorer's own area of specialisation. If required this includes the ability to carry out or manage actions in order to collect information demonstrating a blurred line between knowledge, skill and competence. This translates into a highly specialised knowledge of the principles, theories and practices of Conservation-Restoration within a particular specialization, an advanced knowledge within areas of specialization that are adjacent to this field, and a comprehensive knowledge of the cultural heritage sector in general. Although unproven, it suggests a normal distribution of knowledge around a particular specialism.

The generic level of skill at EQF Level 7 is:

Specialised problem solving skills required in research and/or innovation in order to develop new knowledge and procedures and to integrate knowledge from different fields. (The European Qualification Framework for Lifelong Learning, European Communities, 2008:12)

Specialised problem solving skills was understood by E.C.C.O. to mean the level of ability required to practice Conservation-Restoration, informed by a highly specialised knowledge and governed by ethics. Such a level of skill is needed to find, adapt or create new knowledge and to carry out procedures within the boundaries of the ConservationRestoration specialization. It includes an ability to observe, collect and critically analyse relevant information in order to reach an appropriate conclusion and carry out an appropriate course of action, which is typically described as conservation treatment. It includes the ability to continuously analyse and evaluate a situation or process in order to make adjustments where needed (during for example treatment); the ability to integrate knowledge from different fields, the ability to create new knowledge and procedures, and, where it arises the ability to communicate knowledge. A proficient level of manual dexterity and sensitivity must be demonstrated when carrying out treatments in the field of specialisation, which may also be transferable or shared between other specialisations within relevant fields. This equates with a cognitive ability to carry out familiar processes within a given specialisation thereby enabling unfamiliar processes to be attempted. It includes a high level of familiarity with methods, materials, tools and instruments within the given specialisation and the ability to adapt and develop new tools and methods to suit new tasks.

The generic EQF definition of competence at Level 7 is:

Manage and transform work or study contexts that are complex, unpredictable and require new strategic approaches. Take responsibility for contributing to professional knowledge and practice and/or for reviewing the strategic performance of teams. (The European Qualification Framework for Lifelong Learning, European Communities, 2008:12)

This has been interpreted by E.C.C.O as: the Conservator-Restorer is competent when he/she has the necessary skills, knowledge and experience to operate in their specialist field within the ethical and practical boundaries of the Conservation-Restoration profession and the situation of the cultural heritage. It represents the ability to work consistently and responsibly, with appropriate caution, within the field of Conservation-Restoration as a whole and involves the application of knowledge and skills as expressed below. It includes 
the ability to use existing Conservation-Restoration concepts, select and carry out remedial and preventive treatment on cultural heritage, create new strategic approaches and apply their principles and ethics in a variety of situations.

It suggests a combination of cognitive, physical, motivational, ethical, volitional and social components and implies a degree of understanding that is sufficiently developed to tackle the complexity of the tasks and demands that must be met. In principle, once a task has been carried out repeatedly over time a level of meta-cognitive competence is achieved which can be expressed as a high level of skill. This demonstrates the blurring of boundaries between skill and competence. For this reason E.C.C.O. chose to use only knowledge and skill as measures in the development of the concept framework, which in combination with motivational, ethical, volitional and social resources becomes the level of competence that defines the professional.

While benchmarking offers a suitable point of departure, the working group recognised that the definitions offered by EQF and interpreted by E.C.C.O. remained ambiguous due to its level of generalisation. Given this obstacle, alternative approaches were investigated. Weinert (2001) considers seven different ways in which competence can be defined, described and theoretically interpreted. Of these, which will not be discussed herein, the theoretical approach that focuses on identifying specialized cognitive competences was considered to be the most applicable. Adopting this approach however was not without its own risks, while it offers a suitable method within which to perceive a profession, such a process is inevitably influenced by what is seen to be valued in a profession and by the goals and norms that it represents. Furthermore, depending on how these competencies are understood a certain vision of a profession can be strengthened or weakened. To a certain extent these potential obstacles could be avoided by identifying individual areas of cognition that have already been examined extensively within the professional literature and by defining general levels of competency without being over prescriptive about how they are reached. This approach suggests that access to a profession is best presented as a framework of interconnected cognitive competencies expressed as a structural process, each with their individual levels of skill and knowledge.

\section{Constructing the competence framework}

The challenge was to define and present the interconnected cognitive competences (combinations of knowledge and skill) in a sufficiently universal format to allow for the plurality of values and professional practice across Europe. This was met by selecting a normative frame of reference presented as different interconnected areas of knowledge and skill required in a typical Conservation-Restoration decision-making process. This forms the basis for the knowledge and skill required to carry out the broad range of practical tasks within conservation. Although practical skill is not overtly identified in the framework it is inherent within each element. This approach was favoured because it represents a broadly accepted process-oriented depiction of the conservator-restorers role, which can be confirmed by a number of well established definitions, for example, Weaver et al. (1950), Heritage Collection Committee (1995), CAC and CAPC (2000). By assuming that sufficient commonality exists between the different fields of Conservation-Restoration, due to universally accepted standard of ethical behaviour and practice, it can be argued that such a depiction is applicable across the entire profession throughout Europe. A recent example of a similar approach within Conservation-Restoration is the work carried out by the European Committee for Standardization, Technical Committee CEN/TC346. 
The adoption of a typical decision-making process within Conservation-Restoration allowed it to be expressed as a series of concepts representing both its practical and academic elements. The process framework describes a pattern of events that is followed, or uniformity of attributes that is examined, representing the way a professional acts or thinks. Identification of these attributes allows the construction of a descriptive framework that encompasses the multifaceted nature of Conservation-Restoration. The conceptualization of such a complex subject was considered feasible only because they shared sufficient regularities due to a common ethical framework. Although the interpretation and importance of each attribute may vary between individuals depending on their experience, circumstances and perspective within cultural boundaries, the basic attribute remains the same. This allows propositions about the profession to be effectively communicated. Such an approach is not, however, without its disadvantages, concepts and their associate propositions rely on conventions which, from a social science perspective, may possess ambiguities, depending on the disciplinary background, ideological stand-point and underlying associations of those who consider them. Great care was therefore exercised during the construction of the conceptual framework to ensure that the key terms are recognisable and understood throughout the Conservation-Restoration profession. Concept Mapping (Novak and Gowin 1984), used to construct the framework, externalizes propositions thereby facilitating understanding, informational exploration and its relational structure. This is achieved by creating a particular picture of reality representing a situation or phenomenon, thereby identifying key concepts together with their relevant interconnectivity. Such a map can then used to identify the different levels of knowledge and skill, from which it is possible, with the appropriate level of familiarity, to characterize any profession.

Within the map, shown in Fig. 1, each concept is represented by a node which is identified by a short name. The links are given a descriptive verb. The combination of nodes and descriptive links form a proposition, which represent a semantic unit (Novak and Canas 2008). In this case these are meaningful statements about different areas of competence. The links are directional and are labelled with a simple explanation of the relationship, thereby creating a hierarchical structure which is similar to other concept maps, in that it moves from the more general to the more detailed. Unlike others, the layout does not show the most inclusive, general concepts at the top and increasingly specific concepts below. Instead the map is presented as a central spine of key decisions, each of which is increasingly divided as the linked semantic units moved away from the spine. Hierarchical semantic units connected to each spinal node are presented to the right of the spine and more general semantic units to the left.

The two features that identify concept mapping as an appropriate tool for modelling the requirements for access to the Conservation-Restoration profession are: its hierarchical structure and its ability to characterize links between areas of competence. During its construction particular attention was given to the linkage terms as there were often two or three equally valid expressions, each with a slightly different connotation. Typical these differences became conspicuous once other propositions had been added. This subtlety of expression confirmed concept mapping as a powerful tool for observing the nuances of meaning associated with the Conservation-Restoration profession.

The concept mapping process was heuristic, during its construction the map was redrawn a number of times in order to correct misconceptions, increase its meaningfulness and add to its negotiated significance. The nature of the map, built up from different individual aspects of Conservation-Restoration facilitated an exchange of views on why a particular propositional link and element of professional practice is relevant and valid. It 


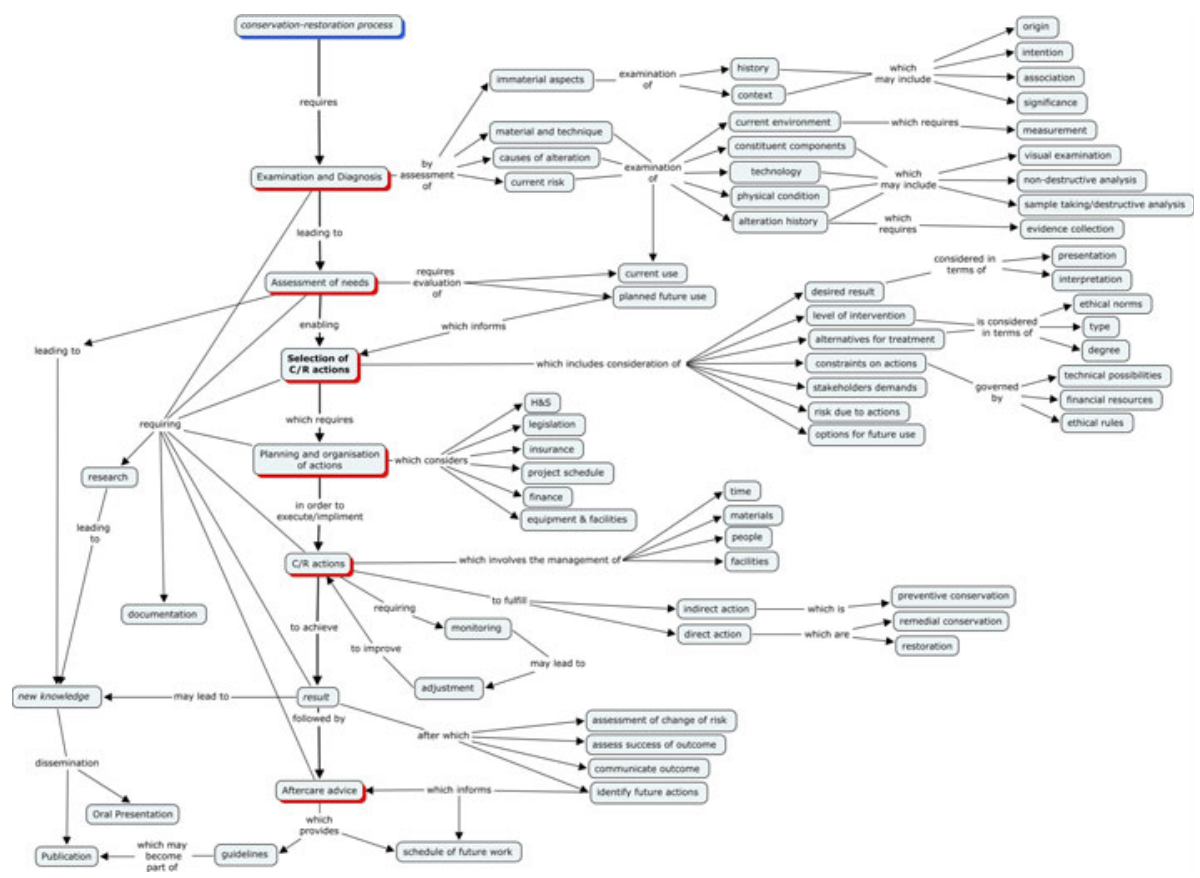

Fig. 1 Area of skill and knowledge required for Conservation-Restoration

allowed the rapid detection of ambiguities and inconsistencies allowing the various propositions to be effectively transmitted and clarified through a process of discussion, consultation and negotiation. This facilitated the group work enabling missing concepts and linkages to be easily identified, thereby exemplifying the effectiveness of this technique as a tool for sharing and agreeing ideas.

The resulting diagram shows a framework of interconnected competencies that describe the attributes that must be possessed by anyone wishing to enter the profession. It is based on a typical Conservation-Restoration process that proceeds via an information gathering stage to direct intervention stage, after which post-intervention options are considered. This represents a typical process from which the various activities involved in both conservation and restoration evolve. The diagram is generic in that it can be applied to any area of specialization in order to make explicit the problem solving nature of Conservation-Restoration. It represents concepts that are linked together to form propositions symbolizing the "negotiated significance" between the different facets of ConservationRestoration. The actual size of each area of skill and knowledge in relation to the perceived duties of a Conservator-Restorer is not defined as this is dependent on the type of work, the type of cultural heritage and its circumstances. While the high level of practical skill associated remedial conservation treatment appears to be solely represented by a limited number of areas within Conservation-Restoration actions, in reality this part of the decision-making map may represent a significant proportion of the work undertaken. The specialist nature of professional Conservation-Restoration is emphasized in particular parts of the map through the assignment of proficient levels of skill, more fully described in the next section. 


\section{Application of a taxonomy of learning}

Having mapped Conservation-Restoration, the next step was to identify the type and level of skill and knowledge for each area of competence that would satisfy entry level to the profession, corresponding to EQF Level 7. This was achieved by overlaying a taxonomy of educational objectives onto the map. The former arranges thinking behaviour into the different categories associated with educational achievement, and is most closely associated with Bloom (1956). It typically uses three domains: The cognitive, the affective and the psychomotor, it is the cognitive domain however that is by far the best established. While it is worth noting that other educational taxonomies and hierarchical systems have been developed, for example, Anderson and Sosniak (1994), it is Bloom's that remains the most broadly accepted and the most widely applied. Since its publication in 1956 this taxonomy has been adopted, revised and reinterpreted widely. One recent revision stands out as meriting particular attention: the work carried out by Anderson and Krathwohl (2001). This represents a significant update of the original taxonomy in line with modern thinking and expresses the taxonomy in the verb forms describing the cognitive process, given below:

1. Remembering: to know something exists and where to find it.

2. Understanding: to be able to comprehend something in its context and make associations between things.

3. Applying: to be able to use knowledge in an appropriate context in order to achieve a desired result in a predictable way.

4. Analysing: to be able to apply knowledge in a critical way using a level of awareness that allows one to explain the results-i.e. to reconstruct how the result was achieved. Decision making comes out of analysis. Analysis comes from an analytical approach but lacks experience.

5. Evaluating: to apply knowledge in order to measure a situation in terms of its broader context and in relation to determining future outcomes. This allows results to be weighed up in terms of decision making and a broader managerial context. Evaluation comes from experience.

6. Creating: a broad width of knowledge and experience which allows one to extend the boundaries of knowledge. This requires highly developed foresight and meta-cognitive understanding. (Anderson and Krathwohl, 2001, pp. 67-68)

In choosing to use these categories it is recognised that each level is a development in learning behaviour that builds on the preceding one. The revised taxonomy introduces an additional dimension of knowledge thereby expanding the descriptive capacity of Bloom's taxonomy. It takes the form of four types of knowledge: factual, conceptual, procedural and meta-cognitive, which represents a scale of increasing complexity. For the purpose of the framework for access to the profession these are summarised as follows:

A. Factual: of or relating to a piece of information presented as having objective reality

B. Conceptual: of or relating to, or consisting of abstract or generic idea generalized from particular instances

C. Procedural: of or relating to a particular way of accomplishing something or of acting

D. Meta-cognitive: transcending (more comprehensive than) conscious intellectual activity-typically exhibited by an experienced practitioner.

While the taxonomy above is strictly hierarchical, the dimensions of knowledge are less so and have therefore been treated as individual categories. In accordance with the 
description of competence given earlier it was also necessary to evaluate the level of skill required. Skill is generally defined as: the proficiency, facility, or dexterity that is acquired or developed through training or experience. It indicates a special ability or expertise enabling one to perform an activity with ease and precision in order to obtain the desired result. The same approach was adopted towards the construction of a suitable scale and evaluation of individual nodes. In this case a widely accepted scale was not available so it was therefore necessary to develop one. In this case a simple four level scale has been constructed, with each level building on the previous one:

1. Basic Skill: is when a person only possesses the ability to carry out basic tasks in a complex conservation-restoration process. They are unlikely to possess an in depth knowledge of any subject area required to carry out the task unsupervised and may not be aware of many of the ethical rules that apply. They operate well within the boundaries that are laid down by the profession (light blue in Fig. 2).

2. Intermediate Skill: is when a person possesses a higher level of skill both in terms of its breadth and depth. They are expected to possess basic skills across the whole field of expertise, be able to place different concepts within that field, and to have knowledge of the rules. They are able to carry out basic conservation tasks unsupervised and work within a team on complex conservation problems (green in Fig. 2).

3. Proficient Skill: is when a person is expected to possess adequate skill to carry out conservation processes autonomously and understands the spirit of the rules that govern that field. They are capable of carrying out Conservation-Restoration tasks and processes to a level that is acceptable within the profession, but may not work as effectively as an experienced Conservator-Restorer and may not possess adequate skill to carry out the most difficult tasks (yellow in Fig. 2).

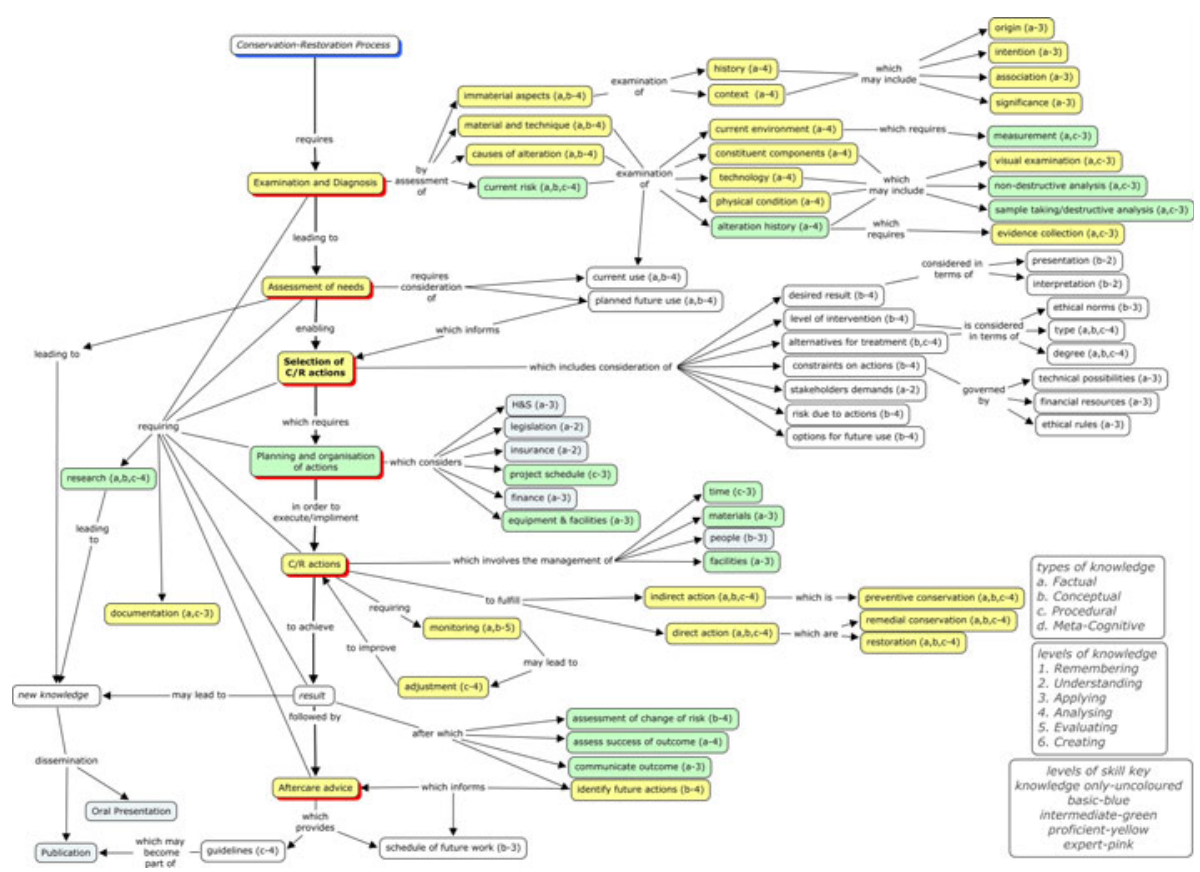

Fig. 2 Level of knowledge and skill required to enter the Conservation-Restoration profession 
4. Expert Skill: is when a person possesses a comprehensive ability to carry out tasks and undertake processes within their field of expertise. They are able to also carry out tasks and undertake processes proficiently in associated fields. They will be able to apply knowledge and the understanding of processes in a new and innovative way and will be able adapt and create new methods within the field of Conservation-Restoration.

With the exception of the central spine, each node, shown in Fig. 1, was given a set of coordinates relating to the level and type of knowledge required to enter the profession. In effect this creates a topographical map of the type and level of knowledge required by someone achieving an EQF Level 7 qualification. A colour was used to identify the level of specialist skill required. Where a node requires only general skills, for example literacy, it was left without colour. The following framework represents the combined level of knowledge and skill required to enter the profession of Conservator/Restorer (equivalent to EQF Level 7):

\section{Conservation-restoration specific descriptors}

In light of the detailed map presented in Fig. 2, a meeting was held on 20th February 2009 between delegates of E.C.C.O. and ENCoRE to decide upon specific descriptors for EQF Level 7, the result of which is:

Highly specialised knowledge is the knowledge in a field of conservation that is only attained following an education that is "an appropriate balance of integrated theoretical and practical teaching...." (The Document of Pavia, 1997, clause 6). Critical awareness of knowledge issues in a field is the ability to acquire knowledge, evaluate its validity and reliability, and apply it, in order to justify all decisions subject to the ConservatorRestorer's own area of specialisation, and if required to carry out or manage actions stemming from these decisions. This translates into a highly specialised knowledge of the principles, theories and practices of conservation within their specialism/field, an advanced knowledge within the fields that are adjacent to their specialism, and a comprehensive knowledge of the cultural heritage sector in general.

Specialised problem solving skills is a level of ability to practice conservation-restoration, informed by highly specialised knowledge and governed by ethics. This is required to find, adapt or create new knowledge and procedures within the boundaries of the conservation-restoration profession. It includes an ability to observe, collect and critically analyse relevant information in order to reach appropriate conclusions and carry out a course of actions; the ability to continuously analyse and evaluate the situation and the process in order to adjust where needed; the ability to integrate knowledge from different fields, the ability to create new knowledge and procedures where it arises; the ability to communicate knowledge. A proficient level of manual dexterity and sensitivity must be demonstrated in the field of specialisation which may also be transferable or shared between other specialisations within relevant fields. This equates with a cognitive ability to carry out familiar processes within a given specialisation, which enables unfamiliar processes to be attempted. It includes a high level of familiarity with methods, materials, tools and instruments within the given specialisation and the ability to adapt and develop new tools and methods.

Competence is when a Conservator-Restorer has the necessary skills, knowledge and experience to operate in their specialist field within the ethical and practical boundaries of the conservation profession and the situation of the cultural heritage. This represents the 
ability to work consistently and responsibly, with appropriate caution within the field of conservation restoration as whole and involves the application of knowledge and skills as represented earlier. It includes the ability to use existing conservation-restoration concepts, create new strategic approaches and apply their principles and ethics in a variety of situations. Having constructed the framework it became a simple task to summarize the skills, knowledge and competence that it represented into more meaningful statements. While these represent the Descriptors required by the EU Commissioner responsible for Education, Training, Culture and Youth, it is not envisaged that they would be used without the interpretive aid of the framework.

\section{Discussion of approach and concluding comments}

By evaluating the conservation-restoration process against the cognitive domains presented in the EQF it has been possible to describe the level of competence required to enter this profession.

The approach developed and the tools used throughout this work have facilitated a negotiated result, which has taken into consideration a wide rage of opinion from members of E.C.C.O. representing the profession. Although not measured, the feedback received, the consensus reached and the ease with which specific descriptors were constructed suggests that the frame of reference is widely acceptable to the profession. This indicates that the process has achieved the desired result, thereby satisfying the first of the issues described in the section on mandate and approach.

The second issue presented earlier focused on the cultural factors shaping the description and understanding of key competences. This is more difficult to evaluate. Although little research has been undertaken to date, there is a perceived diversity of approach to Conservation-Restoration within Europe. E.C.C.O. has a membership that encompasses this spectrum. Without describing their precise nature a rough division can be made between Southern and Northern Europe, and Eastern and Western Europe. These regional differences obviously lead to variation in perception and understanding of the level of skills and knowledge required to enter the profession. The lack of discernable regional trends in the response received to the framework, with no one region objecting to a particular aspect of the competences, indicates that it is universally applicable. It confirms that the goal of producing descriptors that are not overly prescriptive both in terms of professional competence and educational delivery has been achieved. The third issue: the lack of linearity between the conceptual model, its interpretation and its implementation within a particular set of circumstances is a matter of future research in which its adoption in a range of countries is examined.

Although not presented in this paper, in applying the Skill and Knowledge scales and categories to EQF Level 7 it became apparent that the levels directly above and below needed to be determined. This had to be done not only within the scope of formal academic education but also with regard to the level of expertise that may be acquired following years of work and continuous professional development (CPD). While Level 6 is below the academic level for access to the profession it was acknowledged that some people may leave education at a Bachelor level, work within the field of Conservation-Restoration and eventually reach a higher level of competence while others may wish undertake a $\mathrm{PhD}$ in this field and then enter the profession. The skills and knowledge required at EQF Levels 6 and 8 were evaluated using the generic descriptors in The European Qualification Framework for Lifelong Learning. What became apparent during this process was that the 


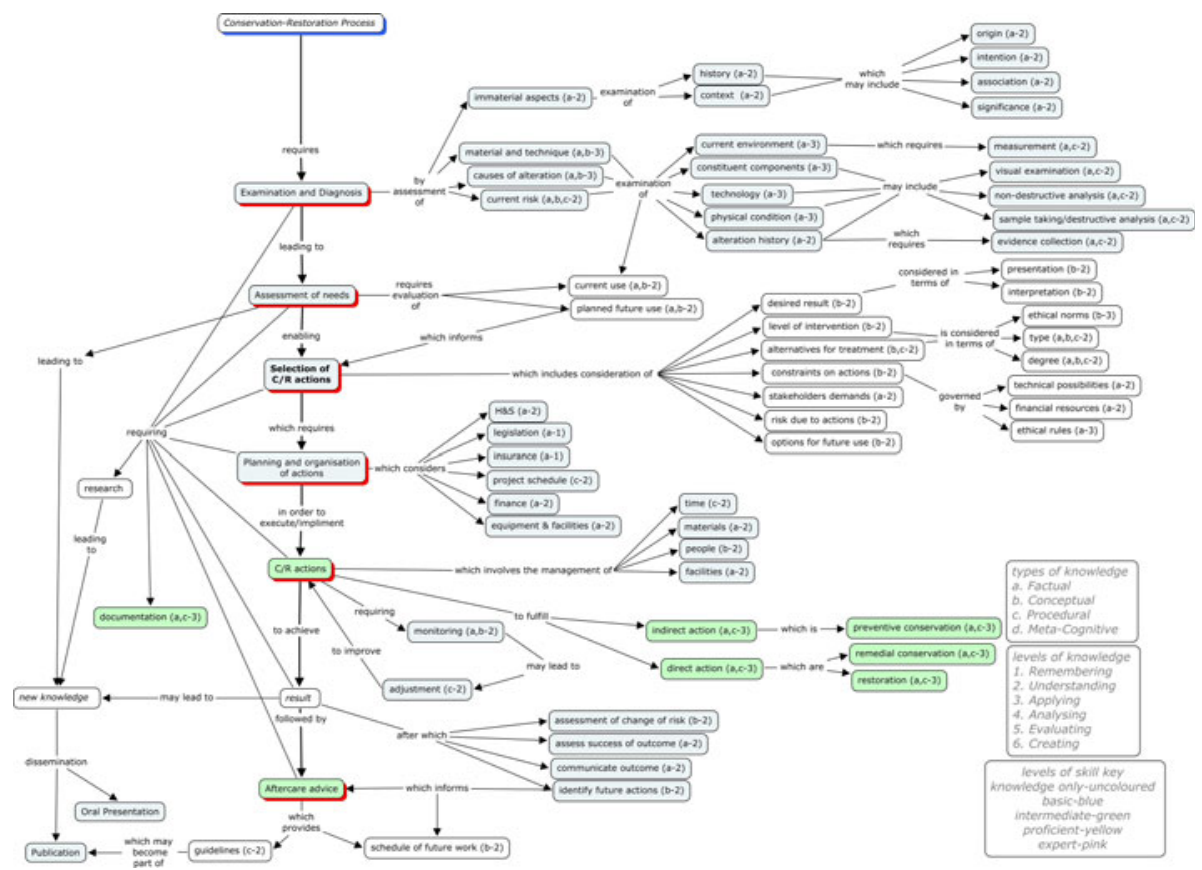

Fig. 3 EQF level 6 knowledge and skills for someone working within the field of Conservation-Restoration

concept map did not need to be altered, what changed was the level of skills and knowledge that was assigned to each node. This added further credence to the structure of the framework, see Fig. 3 below for EQF level 6 knowledge and skills:

In conclusion, the use of a well known and widely applied scale of knowledge enhances the legibility of this concept map for educational programmes wishing to meet the access requirements of the profession. While it offers a detailed description of what is required, the combination of concept map and cognitive scale avoids being overly prescriptive about how and the order in which each of these elements are achieved. It offers a flexible approach towards entering Conservation-Restoration that recognises the variety of educational pathways that allow access to the profession. It also recognises the diversity of educational approaches and syllabus within the different European Conservation-Restoration programmes, even when they award the same level of qualification. The framework offers an added benefit that was not considered at the start of the project: Potentially it could also be used as an evaluation tool for both assessing the quality of individual courses and for identifying where additional education is required for an individual wishing to enter the profession.

Acknowledgments While the authors of this paper are Jeremy Hutchings and Susan Corr, the framework represents the intellectual endeavours of the whole working group. The members include: Mechthild NollMinor, Germany, David Aguilella-Cueco, France, Jaap van der Burg, Netherlands and Agnés Gall Ortlik, Catalonia. Collectively there was enormous good will, generosity of time and knowledge that marked every stage of the framework's development. Great thanks are also due to all who collaborated and gave feedback during the consultation phase. Thanks are also extended to René Larsen who hosted the E.C.C.O./ENCoRE meeting which took place in Copenhagen in February 2009 where the descriptor for EQF Level 7 was agreed. 
Open Access This article is distributed under the terms of the Creative Commons Attribution Noncommercial License which permits any noncommercial use, distribution, and reproduction in any medium, provided the original author(s) and source are credited.

\section{References}

Anderson, L. W., \& Krathwohl, D. R. (Eds.). (2001). A taxonomy for learning, teaching and assessing: A revision of Bloom's Taxonomy of educational objectives: Complete edition. New York: Longman.

Anderson, L. W., \& Sosniak, L. A. (Eds.). (1994). Bloom's taxonomy: A forty-year retrospective. Ninetythird yearbook of the National Society for the Study of Education, Pt.2. Chicago, IL.: University of Chicago Press.

Bloom, B. S. (1956). Taxonomy of educational objectives, Handbook I: The cognitive domain. New York: David McKay Co Inc.

CAC and CAPC. (2000). Code of ethics. Canadian Museums Association. Ontario: The Canadian Association for Conservation of Cultural Property (CAC) and The Canadian Association of Professional Conservators (CAPC).

CON.BE.FOR. (2000). Conservator-restorers of cultural heritage in Europe: Education centers and Institutes. Lurano: Conbefor Ricerca Comparata Associazione Giovanni Secco Suardo.

E.C.C.O. (2004). Professional guidelines III basic requirements for education in conservation-restoration, adopted by its General Assembly, Brussels 2, April 2004.

E.C.C.O. (2009). Report on the Questionnaire review of information on E.C.C.O. member organisations 2008. Internal document, March 2009.

ENCoRE. (1997). The Document of Pavia, preservation of cultural heritage: Towards a European profile of the conservator-restorer. Pavia: Associazione Giovanni Secco-Suardo. October 18-22, 1997, http:// www.encoreedu.org/encore/DesktopDefault.aspx?tabindex=1\&tabid=188. Accessed January 5, 2010.

ENCoRE. (2001). Clarification of conservation/restoration education at University level or recognised equivalent, Unanimously approved by the third General Assembly of ENCoRE 3rd General Assembly, June 19-22, 2001. Munich, Germany.

ENCoRE, E.C.C.O. (2004). Professional guidelines III basic requirements for education in conservationrestoration, adopted by its General Assembly, Brussels 2, April 2004.

EU. (1999). The Bologna declaration of 19 June 1999, joint declaration of the European Ministers of Education Recommendation of the European parliament and of the council of 23 April 2008 on the establishment of the European qualifications framework for lifelong learning, Official Journal of the European Union 2008/C 111/01.

European Community. (2008). The European qualification framework for lifelong learning. Luxembourg: Office for Official Publications of the European Communities.

Heritage Collections Committee. (1995). http://www.cmc.gov.au/working_groups/past_working_groups/ heritage/heritage_heritage_collections_committee. Accessed January 5, 2010.

Larsen, R. (2008). Conservation-restoration education in the light of the European qualification framework for life long learning. Journal of Conservation-Restoration Education, 1, 5-8.

Lester, S. (1999). Professional bodies, CPD and informal learning: The case of conservation. Continuing Professional Development, 3(4), 110-121.

Novak, J. D., \& Caňas, A. J. (2008). The theory underlaying concept maps and how to construct and use them. Technical report IHMC Cmap Tools 2006-01 rev 01. 2008.

Novak, J. D., \& Gowin, D. B. (1984). Learning how to learn. New York: Cambridge University Press.

Novak, J. D., \& Musonda, D. (1991). A twelve-year longitudinal study of science concept learning. American Educational Research Journal, 28(1), 117-153.

Weaver, J. R. H., Stout, G. L., \& Coremans, P. (1950). Report of a confidential inquiry into the cleaning and care of pictures in the national gallery. Unpublished extracts published in Museum, 3(2), 113-176.

Weinert, F. E. (2001). Defining and selecting key competences. Concept of competence. A conceptual clarification. In D. S. Rychen \& L. H. Salganik (Eds.), Defining and selecting key competencies. Cambridge (State of Washington) and Göttingen: Hogrefe \& Huber. 